\title{
Study on the Effects of Forest VR Contents on Stress Relief and Relaxation
}

\author{
ChoungHun Lee, Jang Jae Huk and Seok Woo Jang \\ Korea Maindtraining Center, Korea mindtraining Center, Juyoung-irea town \\ bulding \#702 , 41, Chungsunro 209gil, Bupyunggu, Incheon, Korea \\ rojur@naver.com,jjh622c@gmail.com,mindtraining@naver.com
}

\begin{abstract}
Stress in modern society brings about anxiety which often leads to psychological illnesses such as depression, sociophobia, and schizophrenia. VR is a technology that has been gaining a lot of attention for its ability to allow users to experience virtual reality $(V R)$ in a virtual environment. Such VR technology has shown various contents in fields such as medicine, education and culture. This study conducted a survey for the purpose of increasing stress relief and relaxation, and based on these results, designed VR contents using forest. In order to test the effects of the newly designed VR contents on relaxation, 30 ordinary people were selected as subjects of experiment. Survey after use showed that it had $70.0 \%$ positive effect on stress relief and $80.0 \%$ positive effect on relaxation. Brainwave changes showed theta wave increase in the frontal lobe and decrease in alpha and beta wave, which are similar to when a person rests comfortably.
\end{abstract}

Keywords: VR, psychotherapy, Brainwave

\section{Introduction}

Today, many people are affected by stress in school, office and home, and the age group that is affected by stress is getting lower. At the moment, Koreans from elementary school students to adults suffer from stress which have negative impact on body and mind. Not all stress is bad, but excessive stress makes body and mind sick. Such excessive stress can bring about psychological instability. Such psychological instability increases possibility of psychological illnesses such as depression, sociophobia, and schizophrenia.

Recently, a new method of psychotherapy called virtual reality is under study. Rehabilitation is also being researched as a technology that can potentially be used in various field.

Virtual reality constructs a virtual environment which is very close to reality by using 360 degrees videos and three-dimensional sound. Users can directly experience events, fantasies and fears that humans experience in real life in a virtual space made by computers, and these virtual spaces feel very real which give the users a sense of immersion. Moreover, external device allows users to interact with the virtual characters and events in virtual reality.[4]

Psychotheraphy using virtual reality was first used in early 1990s to treat fears and phobias such as aviophobia and acrophobia. Clients with panic disorder can gradually overcome it using VR, and acrophobia can also be overcome and cured in a safe manner using VR[1][2]. VR is convenient and economic as it can be used on patients with no limits of safety or space. Recently, there have been many successful researches on psychotherapy using VR.[3] VR helps patients to solve their problems step by step and maximizes immersion of the client[5]. The main principle of VR psychotherapy is "recognition behavior exposure therapy," and VR environment is reconstructed using this principle which ultimately allows the client overcome their fears through repeatedly experiencing the unstable factor on the intensity and duration that are suited to the 
patient[6]. VR psychotherapy shows that it has a sustainable treatment efficiency by increasing the client's self-efficacy and making them less aversive towards their fears.[7]

Therefore, the assumption was made that VR not has positive impact on mental patients but also on ordinary people in reducing stress. The purpose of this study is to find out the extent of effect of VR on ordinary people's stress relief. Moreover, the most suitable content was selected, designed and carried out in order to assess its actual efficiency.

\section{Experiment Method}

\subsection{Survey on VR Contents Preference}

This study conducted a survey for the purpose of selecting the VR contents that have the highest stress relief and relaxation effects. Scenes of nature, which are generally known to be good at stress relief, were explored. Forest, ocean, sky, famous buildings and hills were selected as options.

Figure 1 shows survey of 100 adults on the question "which would you most prefer for stress relief and relaxation?" showed that 57 people preferred forest, 26 ocean, 4 sky, 2 famous buildings, all 1 and 0 unanswered. Therefore, forest was selected as the VR content.

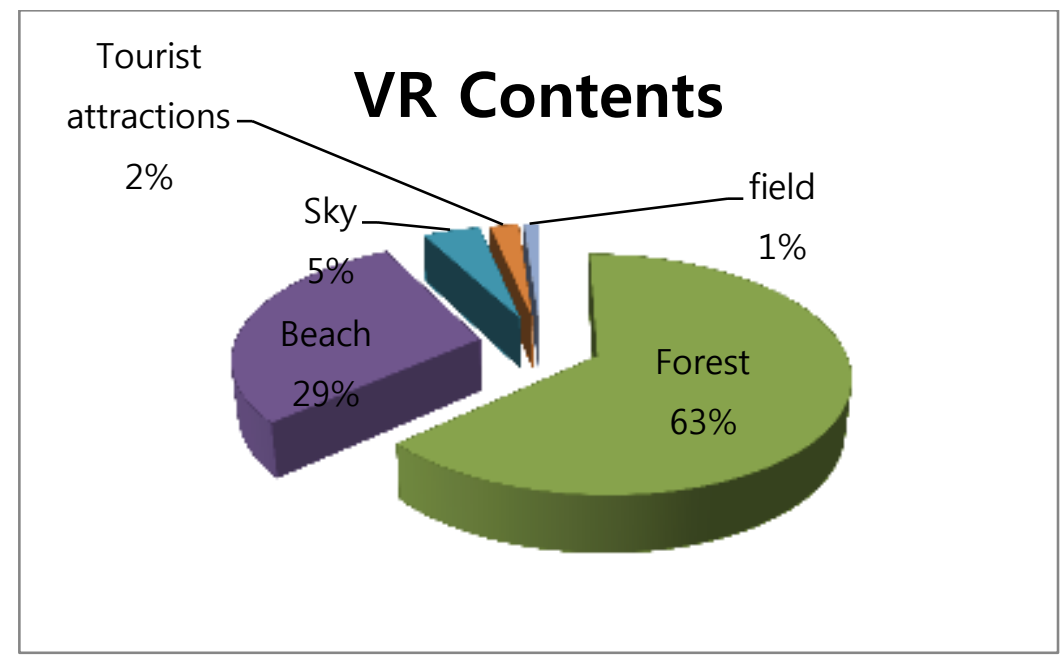

Figure 1. VR Content Evaluation Survey

\subsection{VR Contents Selection and Making}

Survey showed forest as the highest preference, so contents development became centered around forest. Forests were first used in 1840s for climate treatment in Germany, and it is known to aid blood circulation and relaxation. Recently, the National Institute of Forest Science introduced forest therapy to treat North Korean defectors' anxiety and stress, and forest therapy on 900 defectors showed 25\% decrease in negative emotions and $13.8 \%$ increase in positive emotions(report material from the National Institute of Forest Science on 12 Nov 2015).

Forest therapy program of the National Institute of Forest Science showed that $37.8 \%$ of patients most preferred forest trail and $34.4 \%$ preferred inside the forest. Foreset therapy is made up of 4 kinds of treatments, namely climate, topography, exercise and color treatment. VR contents were made based on these 4 components. Omnicns, a domestic contents development specialist, produced the VR based on forest. The virtual forest included lots of grass and trees to give the feel of walking through the forest, and included many great sceneries for an experience that feels more real.

Table 1 shows climate therapy which involves walking in the cool breeze, and VR 
contents production used coniferous forests for this. Topographic therapy involves walking on slopes at a constant speed, which VR also made possible. Exercise therapy activates the body by walking through the forest, and it includes walking as well as breathing. VR allowed for slow breathing. Color therapy uses the effect of colors, and VR uses flowers, insects, and day and night to change colors that the users experience. Figure 2 shows the designed forest. (a) is forest in the morning, (b) is forest in the afternoon, (c) forest at night and (d) forest on a cloudy day.

In order to measure the effectiveness of VR contents on stress relief and relaxation, survey was conducted after the use of VR contents, and brainwave test was conducted before and after in order to measure the changes in bio-signals. The purpose was to find out the intensity of change in brainwaves to determine the effectiveness of forest VR contents on relaxation.

Table 1. Apply to Forest Healing Therapy Composition and VR Content

\begin{tabular}{|l|l|l|}
\hline Configuration & \multicolumn{1}{|c|}{ Contents } & \multicolumn{1}{c|}{ Applying VR content } \\
\hline $\begin{array}{l}\text { Climate } \\
\text { therapy }\end{array}$ & Exposure to fresh wind and negative ions & $\begin{array}{l}\text { Various forests are selected, forest } \\
\text { trees are mainly conifer-like trees } \\
\text { such as fir, weather is fine, cloudy, } \\
\text { etc. }\end{array}$ \\
\hline $\begin{array}{l}\text { Topography } \\
\text { therapy }\end{array}$ & $\begin{array}{l}\text { Walk the slope according to the set speed } \\
\text { and distance }\end{array}$ & $\begin{array}{l}\text { Allows the forest to walk a certain } \\
\text { distance at a constant speed }\end{array}$ \\
\hline $\begin{array}{l}\text { Exercise } \\
\text { therapy }\end{array}$ & $\begin{array}{l}\text { Walking through the forest and activating } \\
\text { the body (breathing, etc.) }\end{array}$ & $\begin{array}{l}\text { Walking through the forest leads to } \\
\text { effective relaxation }\end{array}$ \\
\hline Color therapy & Utilizing the effects of color & $\begin{array}{l}\text { Use the time difference such as day and } \\
\text { night to change the color of the forest. } \\
\text { Make the color effect in the surrounding } \\
\text { environment of sunlight, flowers, } \\
\text { insects and other forests. }\end{array}$ \\
\hline
\end{tabular}

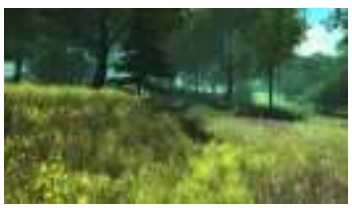

(a)

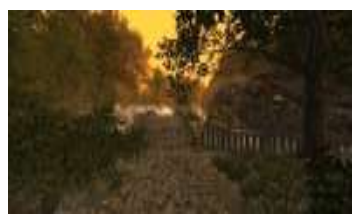

(c)

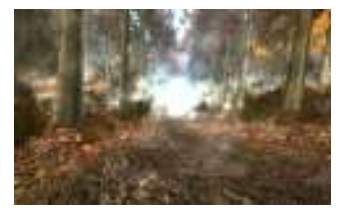

(b)

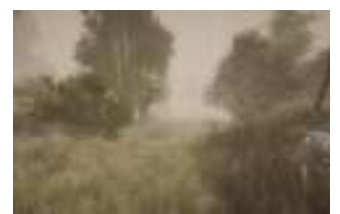

(d)

Figure 2. Created Forest VR Content

Brainwave test was conducted in a quiet laboratory where sounds and light were shut out and the subject can lay down on a comfortable chair, close their eyes and relax. Physical movements were controlled as much as possible to reduce artifacts. Brainwaves were measured using QEEG-8(Laxtha, Inc. Korea), and measuring electrodes were attached on Fp1, Fp2, F3, F4, T3, T4, P3, P4 based on International 10/20 electrode system and were measure for 5 minutes. The experiment was conducted on 30 ordinary people and were measured in the same way before and after the therapy. 


\section{Results of Experiment}

30 adults of both genders (average age is 40.2) were put through brainwave test before they experienced a 10-minute long VR contents. Their brainwaves were tested one more time afterwards and they completed a satisfaction survey. Brainwaves were measured before and after the VR for 5 minutes using 8 channels while the subjects closed their eyes. Brainwaves were measured spontaneously by attaching numbers 1 to 8 to Fp1, Fp2, F3, F4, T3, T4, O1, O2 in that order.

Survey showed satisfaction to be very effective for stress relief(7), effective(14), average(6), not effective(2), very not effective(1). There were 21 positive responses, which make up $70.0 \%$ of the subjects. For relaxation, it showed very effective(9), effective(15), average(5) and not effective(1), very not effective(0). There were 24 positive responses, which make up $80.0 \%$ of the subjects.

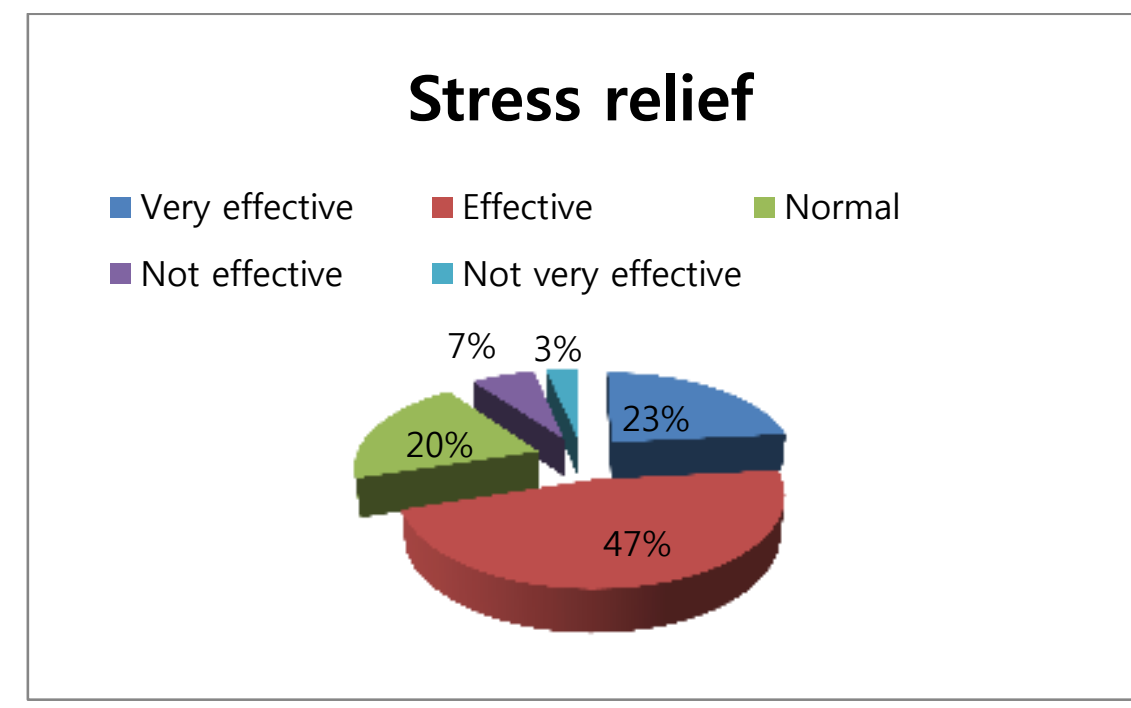

(a) Result of stress relief

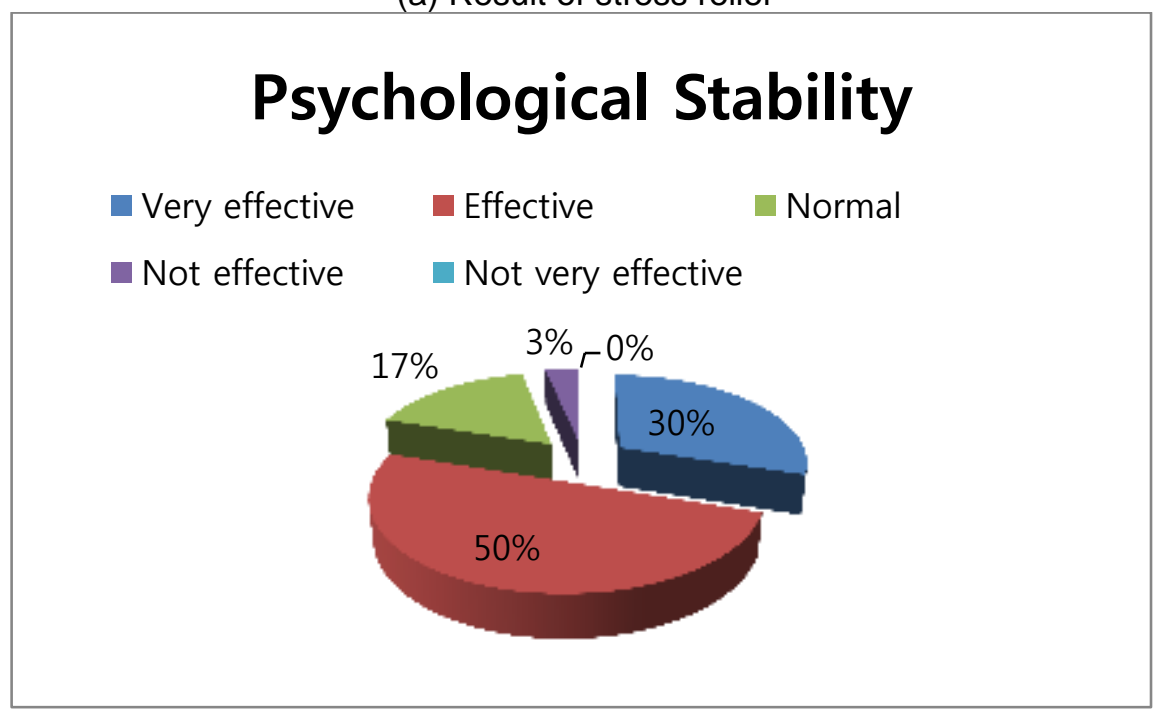

(b)Result of psychological stability

Figure 3. Stress Relief and Satisfaction of Mental and Physical Stability

Theta wave measurement showed increases in Fp1 and Fp2 which correspond to prefrontal lobe, and showed a particularly statistical difference in Fp1. <Table 2> Theta waves in occipital lobe $(\mathrm{O} 1$ and $\mathrm{O} 2)$ showed a trend of reduction. Theta waves are brainwaves which occur during sleep or deep meditation. Increase in theta waves in 
prefrontal which control thoughts show that VR contents relaxed the tension and made the subject feel more comfortable. <Table 3> shows measurement of alpha waves. It is a comparison between before and afte the VR exposure, and it showed reduction of alpha waves in Fp1 and Fp2. Moreover, it showed a meaningful increase in $\mathrm{O} 1$ and O2. Alpha waves occur when a person is resting or concentrating. After the use of VR, the increase in theta waves led to a relative decrease in alpha waves. Occipital lobe is related to sight, and when measured while closing one's eye, alpha waves tend to increase. The increase of alpha waves in occipital waves means that VR led to a visual stability.

$<$ Table 4> shows measurement of beta waves. There was a meaningful reduction in beta waves in the prefrontal lobe(Fp1, Fp2). If there is a high amount of theta waves in prefrontal lobe, alpha and beta waves decrease as a result. There was a meaningful increase in beta waves in parietal lobe, and parietal lobe is a cerebral cortex that is related to physical exercise and senses. In other words, experiencing virtual reality through the VR contents activated all 5 senses and activated the sensory and physical parts.

$$
\left(p^{\star}<.05, p^{\star \star}<.01\right)
$$

Table 2. Theta Wave EEG Results

\begin{tabular}{|c|c|c|c|c|c|}
\hline \multirow{2}{*}{ Channel } & \multicolumn{3}{|c|}{ Before } & \multicolumn{3}{c|}{ After } \\
\cline { 2 - 6 } & Ave & SD & Ave & SD & $p$ \\
\hline Fp1 & 15.71 & 2.58 & 18.15 & 3.52 & 0.03 \\
\hline Fp2 & 15.76 & 2.87 & 17.94 & 3.77 & 0.14 \\
\hline F3 & 16.59 & 2.94 & 16.50 & 2.72 & 0.9 \\
\hline F4 & 16.20 & 3.91 & 16.82 & 3.19 & 0.903 \\
\hline P3 & 14.41 & 3.37 & 14.34 & 3.32 & 0.932 \\
\hline P4 & 14.59 & 3.05 & 14.19 & 3.38 & 0.625 \\
\hline O1 & 12.80 & 3.22 & 11.56 & 3.67 & 0.17 \\
\hline O2 & 13.67 & 2.64 & 11.41 & 4.18 & 0.16 \\
\hline
\end{tabular}

$$
\left(p^{\star}<.05, p^{\star \star}<.01\right)
$$

Table 3. Results of ALPHA EEG Measurements

\begin{tabular}{|c|c|c|c|c|c|}
\hline \multirow{2}{*}{ Channel } & \multicolumn{3}{|c|}{ Before } & \multicolumn{3}{c|}{ After } \\
\cline { 2 - 6 } & Ave & SD & Ave & SD & $p$ \\
\hline Fp1 & 31.40 & 3.34 & 26.91 & 6.76 & .002 \\
\hline Fp2 & 31.53 & 3.89 & 28.37 & 6.51 & .027 \\
\hline F3 & 40.61 & 5.25 & 41.31 & 5.42 & .699 \\
\hline F4 & 40.56 & 5.27 & 41.31 & 6.48 & .628 \\
\hline P3 & 34.00 & 6.34 & 31.94 & 7.12 & .242 \\
\hline P4 & 33.21 & 5.63 & 31.55 & 7.02 & .324 \\
\hline O1 & 43.89 & 8.46 & 52.42 & 8.85 & .000 \\
\hline O2 & 46.64 & 8.50 & 53.59 & 8.43 & .002 \\
\hline
\end{tabular}




$$
\left(p^{\star}<.05, p^{\star \star}<.01\right)
$$

Table 4. Vepea EEG Measurement Result

\begin{tabular}{|c|c|c|c|c|c|}
\hline \multirow{2}{*}{ Channel } & \multicolumn{3}{|c|}{ Before } & \multicolumn{3}{c|}{ After } \\
\cline { 2 - 6 } & Ave & SD & Ave & SD & $p$ \\
\hline Fp1 & 21.71 & 3.04 & 15.88 & 2.96 & .000 \\
\hline Fp2 & 20.51 & 3.35 & 16.50 & 5.03 & .001 \\
\hline F3 & 20.35 & 3.13 & 19.89 & 4.24 & .632 \\
\hline F4 & 20.37 & 2.19 & 19.78 & 3.45 & .422 \\
\hline P3 & 22.16 & 2.93 & 27.62 & 4.61 & .000 \\
\hline P4 & 21.65 & 3.27 & 26.97 & 4.28 & .000 \\
\hline O1 & 20.03 & 4.86 & 19.83 & 3.96 & .063 \\
\hline O2 & 20.68 & 4.46 & 18.79 & 3.68 & .079 \\
\hline
\end{tabular}

Overall, VR experience showed increase of theta waves in prefrontal lobe and decrease of it in the occipital lobe. There were some differences, but it can be said that the common differences in brainwaves were the result of the 10-minute long VR experience, and it gives a general relaxation and stress relief effect.

\section{Conclusion}

Survey found forest to be potentially most effective in stress relief and relaxation. Forests were made by VR in the form of morning, afternoon and night, and were experienced by 30 subjects and tested for satisfaction and changes in brainwaves. Satisfaction survey showed $80.0 \%$ to be effective in relaxation and $70.0 \%$ to be effective in stress relief. Survey found forest to be potentially most effective in stress relief and relaxation. Forests were made by VR in the form of morning, afternoon and night, and were experienced by 30 subjects and tested for satisfaction and changes in brainwaves. Satisfaction survey showed $80.0 \%$ to be effective in relaxation and $70.0 \%$ to be effective in stress relief. There were changes in the subjects' brainwaves. Brainwave changes showed theta wave increase in the frontal lobe and decrease in alpha and beta wave, which are similar to when a person is resting comfortably. This shows that forest VR contents increased theta wave in the frontal lobe. High values in beta wave in parietal lobe shows that VR activates the senses in the subjects' bodies. This research showed that VR contents had positive impact on ordinary people's stress relief and relaxation. The result of this research will help many people in today's society relieve their stress and relax by using VR contents. VR contents will continue to develop and diversify so that it will affect people's bodies and minds, and will be used extensively in the field of psychotherapy.

\section{References}

[1] "Overcoming Phobia by Virtual Exposure", D. Strickland, Larry Hodges, Max North and Suzanna Weghorst, 1997, Comm.ACM, Vol40, No.8, pp.34-39

[2] "Virtual Reality Therapy: An Effective Treatment for Psychological Disorders", Max M. North, Sarah M. North, and Joseph R. Coble, 1997, Virtual Reality in Neuro-Psycho-Physiology IOS Press

[3] "Development of A Virtual Reality Psychotherapy System", Jeonghun Ku, 2000, Dept. of Biomedical Eng. Graduate School Hanyang university, p. 2

[4] "VIRTUAL REALITY: Fusion of virtual and reality after mobile trend view", Kim Jonghyeon, 2016, 
Virtual reality (VR) Korea Seminar presentation material.

[5] "Analysis of research trends in Virtual Reality Therapy: for overseas journals", Kim Sua, 2017, Graduate School of Integative Medicine Sunmoon university , Master's Thesis, P 23-24

[6] "Virtual reality therapy: Computer-Assisted and Web-Based innovations in Psychology", North, M. M \& North, S. M, 2016, Special Education, and Health, pp 139- 141

[7] "Virtual reality in mental health" Gregg, L. \& Tarrier, N., 2007, Social psychiatry and psychiatric epidemiology, 42, pp 343-354

[8] "The Effects of Music Therapy on the Changes of Brain Waves, Emotion, Depression and Reduction of Anxiety for the Posttraumatic Stress Disorder Patients", Hyoung Joon Park,2007, Won Kwang University, p 16

[9] “A Virtual Reality Exposure Therapy Application for Iraq War Post Traumatic Stress Disorder”, Jarrell Pair, Brian Allen, Matthieu Dautricourt, Anton Treskunov, Matt Liewer, Ken Graap*, Greg Reger \& Albert Rizzo, Virtual Reality Conference, 2006. 07. August

[10] "A Randomized, Controlled Trial of Virtual Reality-Graded Exposure Therapy for Post-Traumatic Stress Disorder in Active Duty Service Members with Combat-Related Post-Traumatic Stress Disorder", Robert N. McLay, M.D., Ph.D, Dennis P. Wood, Ph.D, Jennifer A. Webb-Murphy, Ph.D, CYBERPSYCHOLOGY, BEHAVIOR, AND SOCIAL NETWORKING Volume 14, Number 4, 2011 
International Journal of Signal Processing, Image Processing and Pattern Recognition Vol. 10, No. 8 (2017) 